\title{
Relapsing Remitting Multipl Skleroz Hastalarında Ekstrakraniyal ve İntrakraniyal Venöz Yapıların Doopler Sonografi, Kraniyal MR Venografi ve Selektif Venografi ile Değerlendirilmesi ve Sağlıklı Kontroller ile Karşılaştırılması
}

\author{
Emine KAYGILI ÖKSÜZ ${ }^{1}$, Ömer Faruk TURAN ${ }^{2}$, Özlem TAŞKAPILIOĞLU ${ }^{3}$, \\ Bahattin HAKYEMEZ ${ }^{4}$, Aylin BİCAN DEMİR ${ }^{2}$ \\ 1 Mersin İl Sağlık Müdürlüğü, Mersin. \\ 2 Bursa Uludağ Üniversitesi Tıp Fakültesi, Nöroloji Anabilim Dalı, Bursa. \\ 3 Bursa Acıbadem Hastanesi, Nöroloji Kliniği, Bursa. \\ 4 Bursa Uludağ Üniversitesi Tıp Fakültesi, Radyoloji Anabilim Dalı, Bursa.
}

\section{ÖZET}

Son yıllarda Multipl skleroz (MS) etyolojisinde, internal juguler ven (IJV) ve/veya azigos venlerde venöz drenaj bozukluğu olarak tanımlanan kronik serebrospinal venöz yetmezliğin (KSSVY) etkili olduğu ileri sürülmektedir. Bu teori, MS etyopatogenezinde etkili olduğu düşünülen otoimmün teoriyi toptan yadsıması nedeni ile ciddi tartışmalar başlatmıștır. Bu teori ile, MS etyopatogenezine farklı açılardan bakılması nedeniyle ilgi çekmiş ve bununla ilgili birçok çalışma başlatılmıştır. Çalışmamızda Doppler sonografi (DS), kranial MR venografi (MRV) ve selektif venografi (SV) ile MS hastalarında KSSVY’nin varlığının tespiti, ekstrakraniyal-intrakraniyal venöz yapıların yapısal- fonksiyonel açıdan incelenmesi, sağlıklı kișilerle karșılaștırılması amaçlanmıștır. 25 Relapsing Remitting MS hastasına DS, SV ve kraniyal MRV yapılırken, 20 sağlıklı kişiye kraniyal MR venografi ve Doppler sonografi yapıldı. Hastalarda DS' de reflü varlığ açısından kontrol grubuna göre istatistiksel olarak anlamlı idi $(\mathrm{p}<0,05 \mathrm{P}=0,001)$. Kraniyal MRV' de intrakraniyal venlerde morfolojik açııdan hasta ve sağlıklı grup arasında istatistiksel olarak anlamlı fark yoktu. Selektif venografide hastaların \%72'sinde sağ IJV'de, \%76'sında sol IJV'de, \%12'sinde azigos vende $\% 50$ ve üzeri darlık saptanırken; hastaların $\% 60$ da sağ IJV de, $\% 48$ inde sol IJV de ve $\% 16$ sinda ise azigos vende \%75 ve üzeri darlık izlendi. Hastaların \%44'ünde azigos vende anomali izlendi. Calıșmamızdaki MS hastalarında KSSVY görülme oranı \%76 idi. Saptamış olduğumuz yüksek orandaki kolateral dolaşım varlığı, hastalarda saptadığımız reflünün bir göstergesi olabilir. Kontrol grubuna etik kurul selekktif selektif venografiye izin vermediği için normalde nasıl olduğunu bilmiyoruz. Bu çalışmada sınırlı sayıda hasta grubunda bu teoriyi destekleyecek darlık bazı hastalarda gösterilmiştir. KSSVY'liğin MS hastasına özgü bir patoloji mi yoksa herkeste olabilecek fizyolojik bir varyasyon olup olmadığını söylemek mümkün değildir. Buna karar vermek için incelemeleri ilerletmek MS ve KSSVY arasındaki ilişkiyi ve/veya bunun MS belirtileri üzerindeki etkilerini saptamak için daha çok sayıda hastada yapılacak geniş çalıșmalara ihtiyaç olduğu düşüncesindeyiz. Bu konuda daha ileri çalışmalara ihtiyaç vardır.

Anahtar Kelimeler: Kronik s erebrospinal venöz yetmezlik. Multipl skleroz. Serebral ven. Intraniyal. Ekstrakaniyal ven.

Evaluation of Extracranial and Intracranial Venous Structures with Doppler Sonography, Cranial MR Venography and Selective Venography in Relapsing-Remitting Multiple Sclerosis Patients and Their Comparisons with Healthy Controls

\begin{abstract}
Chronic cerebrospinal venous insufficiency (CCSVI), defined as impaired drainage at internal juguler vein (IJV) and/or azygos veins, has been accused of as an etiological factor in multiple sclerosis (MS) recently. This theory has initiated serious discussions due to negation of the autoimmune theory in MS. With this theory, MS etiopathogenesis has attracted attention due to its different perspectives and many studies have been started. A lot of studies are being conducted at many centers and conflicting results have been reported recently. We aimed to evaluate extracranial and intracranial venous structures by Doppler sonography (DS), cranial MR venography (MRV), and selective venography (SV) for the presence of CCSVI in MS patients and compare the results with healthy subjects. DS, SV and cranial MRV were performed in 25 relapsing-remitting MS patients' whereas cranial MRV and DS were performed in 20 healthy subjects. We found significantly more reflux in MS by DS than the control group $(p<0.05, p=0.001)$. There was no significant difference in the intracranial veins by cranial MRV between two groups. Presence of $50 \%$ or more stenosis, detected by selective venography, in right IJV, left IJV, and azygos vein was in $72 \%, 76 \%$, and $16 \%$ of MS patients, respectively. Presence of seventy five or more- stenosis in right IJV, and left IJV was detected in $60 \%$ and $48 \%$ of MS patients, respectively. There was azygos vein anomaly in $44 \%$ of MS patients. The CCSVI rate in our study was $76 \%$ in MS patients. The high rate of collateral circulation that we detected may be an indication of the reflux we detected in patients. Presence of stenosis supporting the CCSVI theory was shown in our study with a limited number of MS patients. Further studies with more patients should be carried out to verify the results. It is not possible to say whether CSSVR is a pathology specific to the MS patient or if there is a physiological variation that may occur in everyone. In order to decide this, we think that more studies are needed in a larger number of patients to further the investigations and to determine the relationship between MS and CSR and / or its effects on MS symptoms.
\end{abstract}

Key Words: Chronic cerebrospinal venous insufficiency. Multiple sclerosis. Cerebral veins. Intra-extracranial veins. 


\section{E. Kaygılı Öksüz, ark.}

Geliş Tarihi: 13.Mayıs. 2020

Kabul Tarihi: 08.Temmuz.2020

Dr. Aylin BICAN DEMiR

Bursa Uludağ Üniversitesi Tıp Fakültesi,

Nöroloji Anabilim Dalı,

Bursa.

Tel: 05324881907

E-Posta: aylinbd@uludag.edu.tr

Yazarların ORCID ID Bilgisi:

Emine KAYGILI ÖKSÜZ: 0000-0003-2826-2822

Ömer Faruk TURAN: 0000-0002-6752-1519

Özlem TAŞKAPILIOĞLU: 0000-0001-8832-7857

Bahattin HAKYEMEZ: 0000-0002-3425-0740

Aylin BICAN DEMiR: 0000-0001-6739-8605

Multipl skleroz (MS); merkezi sinir sisteminin (MSS) inflamasyon, demiyelinizasyon, aksonal kayı ve gliozis ile seyreden, ak madde tutulumun ön planda olduğu, korteks ve derin gri maddeyi de etkileyebilen fokal demiyelinize plaklarla karakterize kronik bir hastalıktır ${ }^{1}$. Genç erişkinlerde en sık nörolojik özürlülük nedeni olan MS'in görülme sıklığı coğrafi konuma göre değişen şekilde 5-200/100.000 bulunmuştur. Hastaların yaklaşık 2/3'ünde başlangıç yaşı 20 ile 40 arasındadır. Çeșitli prevalans çalıșmalarında kadın/erkek oranı 2-3/1 olarak bildirilmektedir. Ülkemizde MS prevalansı ve insidansı net olarak bilinmemektedir, ancak Edirne'de yapılan bir epidemiyolojik çalışmada MS prevalansı 100.000'de 34 iken Maltepe merkezli çalışmada ise 100.000 'de 101 olarak bulunmuştur ${ }^{2}$.

Etiyolojisi henüz net olarak bilinmemekle birlikte, son yıllarda yapılan çalışmalar, birçok farklı immün mekanizmanın demiyelinazasyon ve aksonal hasarlanmaya yol açtığını göstermiştir ${ }^{3}$. Hastalığın en önemli özelliği heterojen olmasıdır. Klinik prezentasyon, seyir, tedavi cevabı ve patolojik bulgular başta olmak üzere birçok yönden hastalar arasında büyük farklılıklar vardır. Bu farklılıklar, MS'in tek bir hastalık olmayıp bir sendrom olarak kabul edilme eğiliminin oluşmasına neden olmuştur.

Günümüzde MS hakkında en fazla kabul edilen görüş, MS'in genetik duyarlılığı olan kişilerde, çevresel faktörlerin (enfeksiyonlar, aşılar, stres, meslek, iklimler) tetiklediği otoimmün bir hastalık olduğu şeklindedir. Fakat son zamanlarda otoimmün teoriye karşı MS hastalarında sık görüldüğü düşünülen internal ve/veya azigos venlerde stenoz ya da diğer anormalliklerin MS etyopatogenezinden sorumlu olduğu iddia edilmekte$\operatorname{dir}^{4}$. Zamboni ve arkadaşlar ${ }^{5}$ kronik venöz yetmezlikte hastalıklarda görülen histolojik değişikliler ile MS'de görülen histolojik değişkliklerin değişikliklerin etkileyici benzerliğinden yola çıkarak ikisinde de patolojinin benzer infamatuar inflamatuar yanit sonucu oluştuğunu ve bunun bozulmuş venöz hemodinaminin kanıtı olduğunu düşünmektedir. İlk kez 2006 y1lında kendi üniversite dergisinde bu konuya değinen Zamboni, kronik venöz hastalıklar ve MS'de demir bağımlı inflamasyonun benzer olduğunu ileri sürmüştür $^{5,6}$.

Son y1llarda Multipl skleroz (MS) etyolojisinde, internal juguler ven (IJV) ve/veya azigos venlerde venöz drenaj bozukluğu olarak tanımlanan kronik serebrospinal venöz yetmezliğin (KSSVY) etkili olduğu ileri sürülmektedir. Bu teori, MS etyopatogenezinde etkili olduğu düşünülen otoimmün teoriyi toptan yadsıması nedeni ile ciddi tartışmalar başlatmıştır. Çalışmamızda Doppler sonografi (DS), kranial MR venografi (MRV) ve selektif venografi (SV) ile MS hastalarında KSSVY'nin varlığının tespiti, ekstrakraniyalintrakraniyal venöz yapıların yapısal- fonksiyonel açıdan incelenmesi, sağlıklı kişilerle karşılaştırılması amaçlanmıştır.

\section{Gereç ve Yöntem}

Bu çalışmaya Uludağ Üniversitesi Tıp Fakültesi Nöroloji Anabilim Dalı'nda Haziran-Ekim 2011 tarihleri arasında, McDonald kriterlerine göre tanı konmuş ve MS Polikliniği'nde takipli 25 RRMS hastası ile 20 sağlıklı gönüllü alındı. Hasta grup, 18-65 yaş aralığında, EDSS‘si 0-5,5 arası olan, son MS atağını 30 gün ve öncesinde geçirmiş olan, başka nörodejeneratif hastalığı, kalp yetmezliği, kronik obstrüktif akciğer hastalığı olmayan, geçirilmiş venöz sinüs trombozu veya idyopatik intrakranial hipertansiyon, alkol kullanımı ve kafa travması öyküsü olmayan gönüllü kişilerden oluşmaktaydı. Sağlıklı kontrol gruba herhangi bir sağlık problemi olmayan hastane çalışanlarından gönüllü olan kişiler dahil edildi. Tüm hastaların fiziksel ve nörolojik muayene yapılıp, EDSS skoru hesaplandı. RRMS'i olan 25 gönüllü hastaya Radyoloji Anabilim Dalı tarafindan kranial MRV, transkraniyalekstrakraniyal venöz DS ve ekstrakraniayal SV yapıldı. 20 kişiden oluşan sağlıklı kontrol grubuna ise kranial MRV ile transkraniyal-ekstrakraniyal venöz DS yapild1.

Çalışma Uludağ Üniversitesi Tıbbi Araştırmalar Etik Kurulu'nca onaylandı (Onam tarihi: 8 Eylül 2011 Karar no: 2011-4/3). Araştırmaya katılanlardan onam yazısı alınd1.

\section{Doppler Sonografi Değerlendirme}

Aplio Toshiba (Tokyo, Japonya) Renkli Doppler USG kullanıldı. İncelemeler tüm hastalara ve sağlıklı kontrol grubuna aynı nöroradyolog tarafindan 7-11 hz lineer prob ile olgular supin pozisyonda, baş kontrolateral çevrilmiş durumda iken yapıldı. Yatar pozisyonda internal juguler venin en geniş olduğu yerden çap, debi ölçüldü. IJV, vertebral venler, derin serebral venlerde reflü bakılıp B mod ile anulus, web, septa, flap ya da stenoz varlığı araştırıldı. Valsalva sırasında ve spontan solunum sirasında en az 0,08 sn'lik geriye kan akımı varlığı, reflü pozitif olarak kabul edildi. 


\section{Kraniyal MRV Değerlendirilmesi}

Kranial MR venografi 3 Tesla Achieva TX MR cihazında (Philips Healthcare; Netherlands) ve 32-kanal faz-array koil sistemi kullanılarak gerçekleştirildi. Hem hasta hem sağlıklı kişilerin intrakraniyal venöz yapıları aynı nöroradyolog tarafından değerlendirildi: İntrakraniyal venler; yüzeyel serebral venlerden superior sagittal sinüs (SSS), kavernöz sinüs (CS), inferior petrozal sinüs (IPS); santral ve nükleer bölgelerin derin venlerinden septal ven, superior talamostriat ven, internal serebral ven (ICV), büyük serebral ven (Galen veni), inferior sagittal sinüs (ISS), Bazal ven (Rosenthal: RV), sinüs rektus, transvers sinüs (TS), sigmoid sinüs (SS), SAV( süperfisial anostomotik venler), IJV, fasiyal ve paraspinal venler incelenip sağlıklı kişiler ile karşılaştırıldı.

\section{Selektif ekstrakraniyal venografi (SV)}

Tüm hastalara anjiografik ünitede lokal anestezi altında kateter venografi işlemi gerçekleştirildi. Görüntüleme, bi-plan flat panel detektör sabit dijital anjiografik sistemi kullanılarak yapıldı (AXIOM Artis; Siemens Medical Systems, Erlangen, Germany). İşlem sirasında nabız sayısı, kan basınc1, elektrokardiyogram ve arteryal oksijen saturasyon değerleri monitörize edildi. Tüm olgularda giriş yeri olarak femoral venöz taraf kullanıldı. 5F venöz introducer yerleştirildikten sonra, 0.035 inç kılavuz tel (Angle Glidewire; Terumo, Tokyo, Japonya) 5F anjiografik kateter (Angle Glidecath veya Kobra 2, Terumo) içerisinden önce IJV'ye ilerletildi. Kateter ucu sigmoid sinüsün hemen altına yerleştirilerek her bir IJV'nin dört ayrı yönde venogramları elde olundu. Daha sonra azigos venöz sisteme girilerek oblik projeksiyonlarda imajlar elde edildi. İşlem sırasında kontrast madde, her projeksiyon için otomatik enjektörle $3 \mathrm{ml}$ hızla, $12 \mathrm{cc}$ non iyonik kontrast madde (Visipaque $320 \mathrm{mgI} / \mathrm{mL}$ ) verilerek elde edildi. Venografi tamamlandıktan sonra introducer çıkartıldı ve giriş yeri hemostazı manuel olarak sağland. Olguların hiçbirinde komplikasyon gelişmedi.

\section{Istatistiksel dĕgerlendirme}

Çalışmanın analizleri SPSS 13.0 for Windows (Chicago, IL.) programında yapılmıştır. Sürekli değer alan değişkenler, ortalama, medyan, minimum ve maksimum değerleri ile birlikte verilmiştir. Sürekli değişkenlerin normal dağılıma uygunluğu KolmogorovSmirnov ve Shapiro-Wilk testi ile incelenmiş olup test sonucunda göre gruplar arasındaki karşılaştırmalarda, verilerin dağılım yapısına Mann Whitney U testi kullanılarak bakılmıştır. Kategorik değer alan değişkenler, sayı ve yüzde ile birlikte verilmiş olup gruplar arası karşılaştırmalarında Pearson ki-kare testi, Yates ${ }^{\text {ec in }}$ düzeltilmiş ki-kare testi ve Fisher"ein kesin ki-kare testi kullanılmıştır. Değiş̧kenler arasındaki ilişkiler korelasyon analizi ile incelenmiş olup Pearson ve Spearman korelasyon katsayıları hesaplanmıştır. Çalışmada $\mathrm{p}<0,05$ istatistiksel olarak anlamlı kabul edilmiştir.

\section{Bulgular}

Çalışmaya katılan 25 RRMS hastasının ve 20 sağlıklı kişinin gruplar arası yaş ve cinsiyet dağılımı Tablo I'de gösterilmiştir. Hastaların ortalama atak sayısı 8(2$15)$ idi. Hastaların 8 (\%32)'inde serebral yerleşimli lezyon varken 17 (\%68)'sinde hem serebral hem de spinal lezyon var idi. Ortalama hastalık süresi 72 ay (12-312 ay), ortalama EDSS skoru 1,98 (0-4,5) idi.

Tablo I. Hasta ve kontrollerin yaş ve cinsiyet dağılımı

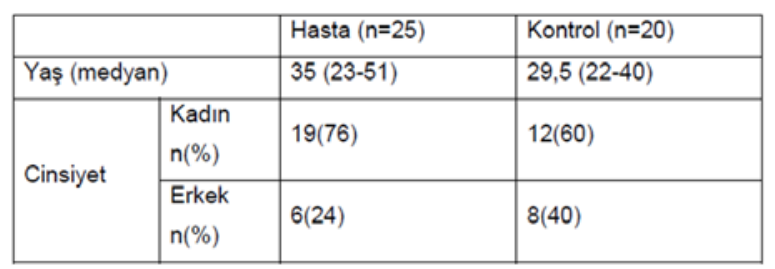

Transkraniyal venöz DS tüm hastalarda ve sağl1klı gönüllülerde normal saptandı. Her iki grupta da intrakraniyal venlerde reflü izlenmedi. Hem hasta hem de sağlıklı grupta ekstrakraniyal DS ile IJV'de anulus, web ya da stenoz izlenmedi. Sağ IJV'de sadece hasta grupta $10(\% 40)$ hastada reflü saptand1. Sol IJV'de reflü, 15 hastada $(\% 60)$ ve 2 sağlıklı (\%10) kişide saptand1. Beş hastada USG'de her iki jugular vende de reflü saptanmadi. Hastaların USG ile IJV'de reflü görülme oranı $\% 80$ idi.

Hastalarda USG ile sağ ve sol IJV'de reflü varlığı, kendi aralarında karşılaştırıldığında istatistiksel olarak anlamlı fark saptanmadı $(\mathrm{p}>0,05)$. Hasta ve kontrol grubunun sağ ve sol IJV'de reflü varlığı açısından karşılaştırılmasında hem sağ hem de sol IJV'de reflü hastalarda istatistiksel olarak anlamlı oranda saptandı $(\mathrm{P}=0,001)$. (Tablo II)

Tablo II. Hasta ve kontrol gruplarının USG ile sağ ve sol IJV reflü varlığının karşılaştırılması

\begin{tabular}{|l|l|l|l|}
\hline & \multicolumn{1}{|c|}{ Sağ IJV reflü $n(\%)$} & Sol IJV reflü $n(\%)$ & $P$ \\
\hline Hasta(n=25) \% & $10(40)$ & $15(60)$ & 0,442 \\
\hline Kontrol(n=20) \% & $0(0)$ & $2(10)$ & --- \\
\hline$P^{*}$ & $0,001^{*}$ & $0,001^{*}$ & \\
\hline
\end{tabular}

*: İstatistiksel açıdan anlamlı

Selektif venografi sonuçlarına göre venöz yapılarda \%50 ve üzeri stenoz varlığı patolojik olarak kabul edilmiştir. Buna göre sağ IJV'de 18 (\%72); sol IJV'de 19 (\%76) hastada stenoz saptandı. Azigos vende 3 (\%12) hastada stenoz saptand1. Hastaların \%60 da sağ IJV de, \%48 inde sol IJV de ve \%16 sinda ise azigos vende $\% 75$ üzerinde ciddi darlık izlendi. Hastaların 11 (\%44)'inde azigos vende septum, membran ve twist saptanmıştır (Şekil 1, Şekil 2). Hastaların IJV'lerinde $\% 50$ ve üzerinde stenoz varlığ kabul edildiğinde hastaların $\% 72$ 'sinde sağ 


\section{E. Kaygılı Öksüz, ark.}

IJV, \%76'sinda sol IJV'de stenoz saptandı. Azigos vende stenoz hastaların \%16 (3 hastada \%50'nin üzerinde darlık vard1)'sinde saptanırken, azigos vende anomali hastaların \%44'ünde bulundu. Anjiografide saptanan stenoz ve USG'de saptanan reflü birlikte ele alındığında Zamboni'nin 5 parametresinden 2'si karş1landığ 1 için çalışmamızda MS hastalarında KSSVY görülme oranı \%76 (19/25) idi. KSSVY saptadığımız MS hastalarını Zamboni'nin tanımladığı KSSVY alt tiplerine göre ayırdığımızda \%8 $(\mathrm{n}=2)$ 'inde tip A, \%16 $(n=4)$ 'sinda tip B, \%52 $(n=13)$ 'sinde tip C KSSVY vard1. Selektif venografide saptanan IJV ve/veya azigosta stenoz ve kollateral dolaşım varlığının hastaların atak sayısı, lezyon yerleşimi, cinsiyet, hastalık yaşı ile karşılatırılmasında sadece hastalık yaşı ile sol IJV'de stenoz arasında istatistiksel olarak anlamlı ilişki vardı. (Tablo III) SV'de saptanan IJV ve/veya azigos vende stenoz ve kollateral dolaşım ve anomali varlığının hastaların EDSS, hastalık yaşı ve atak sayısı ile karş1laştırılmasında; bahsedilen anomali varlığı ile EDSS ve atak sayısı arasında istatistiksel olarak ilişki saptanmazken sol IJV'de stenoz varlığı ile hastalık yaşı arasında istatistiksel olarak anlamlı ilişki bulundu $(\mathrm{P}=0,025 \mathrm{p}<0.05)$. (Tablo IV)

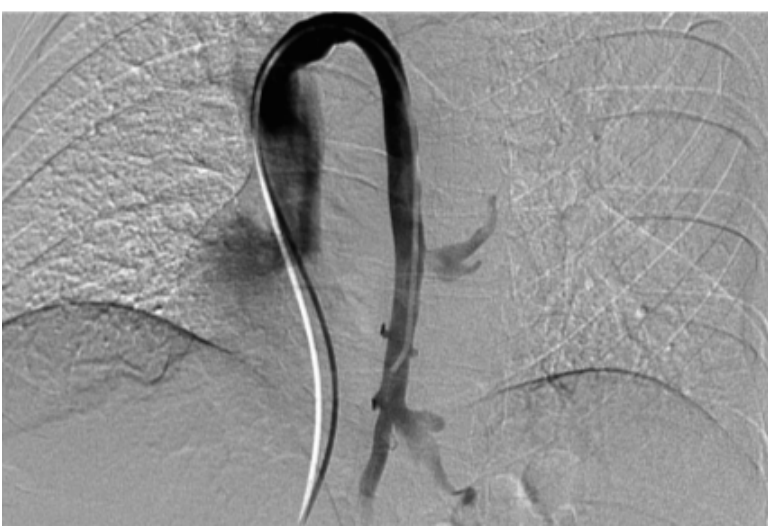

Şekil 1.

Normal Azigos ven

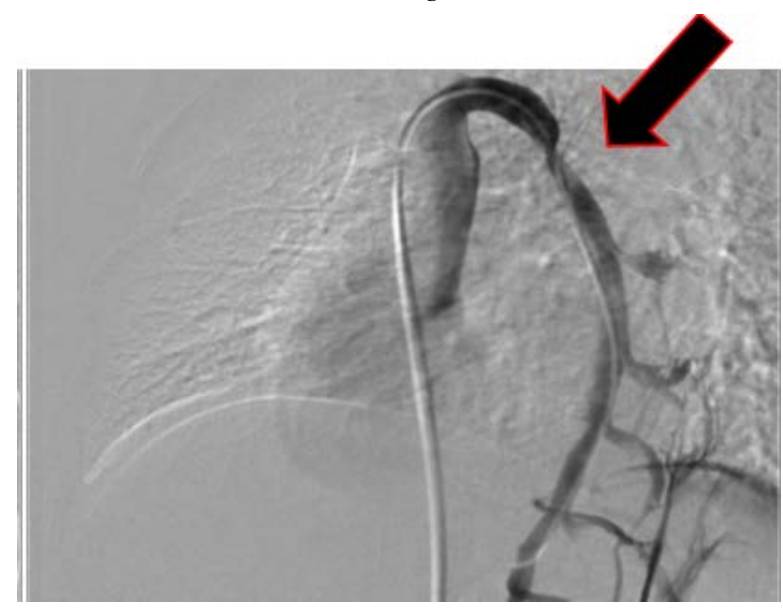

Şekil 2.

Azigos ven twisting grade III darlık
Tablo III. Hastaların SV sonuçlarının hastaların atak sayısı, lezyon yerleşimi, cinsiyet, hastalık yaşı ile karşılaştırılması

\begin{tabular}{|l|l|l|l|l|l|l|}
\hline Hasta & $\begin{array}{l}\text { Sag ijv } \\
\text { stenoz }\end{array}$ & $\begin{array}{l}\text { Sag jiv } \\
\text { kollateral }\end{array}$ & Sol ijv stenoz & $\begin{array}{l}\text { Sol jiv } \\
\text { kollateral }\end{array}$ & $\begin{array}{l}\text { azigos v } \\
\text { stenoz }\end{array}$ & $\begin{array}{l}\text { azigos v } \\
\text { anamoli }\end{array}$ \\
\hline EDSS & $\mathrm{P}=0,029$ & $\mathrm{P}=1,000$ & $\mathrm{P}=0,555$ & $\mathrm{P}=0,677$ & $\mathrm{P}=0,503$ & $\mathrm{P}=0,434$ \\
\hline $\begin{array}{l}\text { Alak } \\
\text { sayııı }\end{array}$ & $\mathrm{P}=0,244$ & $\mathrm{P}=0,642$ & $\mathrm{P}=0,828$ & $\mathrm{P}=0,978$ & $\mathrm{P}=0,979$ & $\mathrm{P}=0,767$ \\
\hline $\begin{array}{l}\text { Lezyon } \\
\text { yeri }\end{array}$ & $\mathrm{P}=\mathrm{P}=0,640$ & $\mathrm{P}=0,618$ & $\mathrm{P}=0,274$ & $\mathrm{P}=0,637$ & $\mathrm{P}=0,387$ & $\mathrm{P}=0,496$ \\
\hline $\begin{array}{l}\text { Hastallik } \\
\text { yașı }\end{array}$ & $\mathrm{P}=0,534$ & $\mathrm{P}=0,113$ & $\mathrm{P}=0,025^{\circ}$ & $\mathrm{P}=0,229$ & $\mathrm{P}=0,894$ & $\mathrm{P}=0,536$ \\
\hline Cinsiyet & $\mathrm{P}=0,637$ & $\mathrm{P}=0,234$ & $\mathrm{P}=0,547$ & $\mathrm{P}=0,626$ & $\mathrm{P}=0,637$ & $\mathrm{P}=0,548$ \\
\hline
\end{tabular}

Tablo IV. Hastaların SV sonuçlarının EDSS, atak sayısı ve hastalık yaşı ilişkisinin değerlendirilmesi

\begin{tabular}{|c|c|c|c|c|}
\hline & & $\begin{array}{l}\text { EDSS } \\
\text { medyan(min-mak) }\end{array}$ & $\begin{array}{l}\text { Atak sayısı } \\
\text { medyan (min-mak) }\end{array}$ & $\begin{array}{l}\text { Hastalik yaşı } \\
\text { medyan (min-mak }\end{array}$ \\
\hline \multirow[b]{3}{*}{ Sağ_jiv_stenoz } & Var $n=18$ & $2,7(0-4,5)$ & $3,5(2-15)$ & $78(12 \cdot 312)$ \\
\hline & Yokn=? & $1,5(0-2,00)$ & $2(2-7)$ & $60(24-120)$ \\
\hline & $P$ & $P=0,029$ & $P=0,244$ & $P=0,534$ \\
\hline \multirow[b]{3}{*}{ Sol_Iiv_stenoz } & Var $n=19$ & $\begin{array}{l}1,5(0-4,5) \\
\end{array}$ & $3(2-15)$ & $96(12-312)$ \\
\hline & Yokn=6 & $1,7(0-3,00)$ & $3.5(2-5)$ & $39(20-72)$ \\
\hline & $P$ & $\mathrm{P}=0.555$ & $\mathrm{P}=0.828$ & $P=0,025^{\circ}$ \\
\hline \multirow{3}{*}{$\begin{array}{l}\text { Azigosv- v. } \\
\text { stenozu }\end{array}$} & $\operatorname{Var} n^{=13}$ & $2(0-4.5)$ & $3(2.15)$ & $T 2(12.312)$ \\
\hline & Yok $n=12$ & $1,5(0-4,0)$ & $3(2-12)$ & $72(24 \cdot 240)$ \\
\hline & $P$ & $P=0,503$ & $P=0.979$ & $P=0,894$ \\
\hline \multirow{3}{*}{$\begin{array}{l}\text { Azigos v. } \\
\text { Anom alisi }\end{array}$} & Var $n=11$ & $2,5(0-4,00)$ & $4(2-8)$ & $72(12-312)$ \\
\hline & Yok $n=14$ & $1,5(0-4,5)$ & $2,5(2-15)$ & $66(22-240)$ \\
\hline & $P$ & $P=0,434$ & $P=0,767$ & $p=0,556$ \\
\hline
\end{tabular}

\section{Tartışma ve Sonuç}

MS, MSS'nin inflamasyon, demiyelinizasyon, aksonal kayıp ve gliozis ile karakterize ak madde etkilenmesinin ön planda olduğu, korteks ve derin gri maddenin de etkilendiği fokal demiyelinize plak varlığ rakterize kronik bir hastalıktır ${ }^{1}$. MS'te kabul gören otoimmün teoriye karşı son zamanlarda MS hastalarında sık görüldüğü düşünülen IJV ve/veya azigos venlerde stenoz ya da diğer anormallik nedeniyle serebrospinal venöz drenajın bozulmasının beyin hasarına, MS gelişimine ve progresyonuna neden olduğu, bu anormalliklerin anjiografik yöntemler kullanılarak açılması ile hastalığın ilerlemesinin durdurulabilineceği iddia edilmektedir ${ }^{7}$.

Literatürde KSSVY varlığını göstermek için birçok nörogörüntüleme kullanılmış olmasına rağmen hangi yöntemin (Doppler sonografi, MRI venografi ya da selektif venografinin) daha iyi olduğu konusunda henüz ortak bir görüş oluşmamıştır. Zamboni ve ark., transkraniyal ve ekstrakraniyal USG kullanarak oluşturulan 5 hemodinamik parametre ile KSSVY tanısı koymanın kontrol grubundan \%100 duyarlılık ve özgüllük ile ayrımının yapılabileceğini iddia etmiştir. Zamboni ve ark. ${ }^{7}$ DS'nin, intralüminal yapısal ve fonksiyonel anomaliyi saptamada daha duyarlı olduğunu belirtirken, Hojnacki ve ark. ${ }^{8}$ da kollateralleri ve stenoz düzeyini göstermede venöz MR anjiografinin daha iyi olduğu fakat duyarlılık ve özgüllüğününün 
belirlenmemiş olduğu vurgulanmıştır. Zamboni ve ark. $^{7}$ anormal stenotik lezyonu göstermek için SV'nin altın stantart yöntem olduğunu vurgulamıştır. Dolic ve ark. $^{9}$ MS hastalarında, MS alt tiplerinde ve sağlıklı kontrol grubunda KSSVY gösterme konusunda DS ve MRV'nin göreceli olarak yüksek özgüllüğe sahip olmalarına rağmen düşük duyarlılığa sahip olduğunu belirtmiştir. MS hastalarında USG'de saptanan bulguların MR venografide bulunan anormallikler ile kombine edilmesi durumunda tanı özgüllüğü \%90'lara çıkacaktır ${ }^{9}$. USG, MS hastalarında KSSVY tanısı koymada \%100 özgül iken IJV'de darlık konusunda MRV ile USG karşılaştırıldığında MRV'nin daha duyarlı olduğu, darlık \%80 üzerine çıktıktan sonra USG'de hemodinamik etkilerinin saptanabildiği sonucuna varılmıştır ${ }^{10,9}$. Traboulse ve arkadaşlarının Kanada'da yaptığı çalışmada 79 MS hastası toplam 177 katılımcinın 171'ine ultrasonografi, 149 katılımcıya venografi katater uygulandı. Sonuçta venöz daralmaların MS'de olası bir neden olmadığını, bunun bir anatomik daralma olabileceğini, MS'li hastalar dahil toplumda venöz daralmanın benzer oranda olabileceği sonucuna varıld $1^{11,10}$.

Çalışmaların çoğunluğunun girişimsel işlemleri içermemesi ve duyarlılığı ve özgüllüğü yüksek olduğu için DS kullanılarak yapılması nedeni ile çalışmamızda DS kullanıldı. Literatürde intrakraniyal venöz yap1ların morfolojisine çok fazla değinilmediği için intrakraniyal venöz yapılar kranial MRV kullanılarak değerlendirildi. Hasta ve sağlıklı grubun karşılaştırılması DS ve kranial MRV ile yapıldı. Hasta grubunu daha ayrıntılı değerlendirmek amacıyla literatürde altın stantart olduğu kabul edilen SV tercih edildi. Çalışmamizda Doppler USG'de IJV'de stenoz ve kollateral, anulus, web, twist, memran gibi anomaliler gösterilememesine karşın SV yapıldığında hastalarda bu venöz anormalliklerden bir kısmını saptadık. Hastalarımızda SV işlemi sırasında ve sonrasında herhangi bir komplikasyon gelişmedi. MS hastalarında KSSVY varlığını taramada, DS'nin kullanılabileceği, bir patoloji saptanması halinde SV ile bunun doğrulanması gerektiği, SV'nin güvenli ve duyarlılığı yüksek bir yöntem olduğu kanaatindeyiz. Zamboni ve ark ${ }^{12,11}$ MS hastaların da herhangi bir pozisyonda DCV'lerde reflü oranın1 \%50, IJV ve/veya VVs'de reflü oranın1 \%70, IJV stenoz oranını USG ile \%28 olarak belirtmiştir.

Al-Omari ve Rousan ${ }^{13}$ tarafından 25 hastanın 23'ünde (\%92) internal jugular vende anormal bulgular bulunmuştur. Baracchini ve ark. ${ }^{14,12}$ klinik izole sendromlu 50 kişiye ve 50 sağlıklı kişiye DS yaptıklarında, herkeste transkraniyal venöz sonografinin normal olduğunu, fakat ekstrakraniyal renkli venöz sonografi ile hastaların \%52'sinde, kontrol grubunun \%32'sinde anormalliler saptandığını belirtmişlerdir. Sundstrom ve ark. ${ }^{15} 21$ RRMS ve 20 sağlıklı kişide faz-kontrast MR ile yaptıkları çalışmada, IJV'de reflü saptamadıklarını, sadece 21 MS hastasından 3 tanesinde IJV'de darlık saptandıklarını belirtmişlerdir. Doppler USG ile 181 MS hastası ve 50 sağlıklı kişide IJV ve VV kan akımı ve morfolojisi değerlendirildiğinde, hastaların \%82 (148/181)'sinde kontrol grubunun ise \%14 (7/50)'ünde ekstrakraniyal jugular vende patolojik değişiklik saptanmıştır. Hasta grupta IJVs ve/veya VVS'de reflü varlığı \% 54, darlık varlığı \% 54, IJV'nin tamamen tıkalı olduğu olgu oranı \% 10, postüral değişiklik ile anormal serebral kan akımı olan olgu oranı \% 25 olarak belirtilmiştir. Doppler USG hem kolay ulaşılabilir olması hem de yüksek duyarılık ve özgüllüğe sahip olması nedeniyle CCSVI patogenezinde ön tarama amaçlı kullanılabileceği vurgulanmıştır $^{16,13}$. Tsivgoulis ve arkadaşlarının 1250 MS'li hasta ve 899 kontrol grubunu içerdiği çalışmada CCSVI sıklığını ultrasonografi ile karşılaştırdı ve MS ile CCSVI arasında anlamlı istatistiksel ilişki bulunmadığı sonucuna varıldı1 ${ }^{17}$.

Kanada ve İtalya'da 6 merkezde 710 MS hastasının katılımı ile venöz USG kullanılarak yapılan çalışmada Zamboni prosedürüne göre IJVs ve VVs reflü oran1 \%75, DCV reflü oranı \%45, IJV'de venöz anormallik (stenoz, anulus septum ) oranı \%80 olarak bildirilmiştir $^{18,14}$. Çalışmamızda intrakraniyal ve ekstrakraniyal venlere baktığımızda; transkraniyal venöz DS tüm hastalarda ve sağlıklı gönüllülerde normal saptandı. Her iki grupta intrakraniyal venlerde reflü izlenmedi. Hem hasta hem de sağlıklı grupta ekstrakraniyal DS'de IJV de anulus web ya da stenoz izlenmedi. Sağ IJV'de sadece hasta grupta, hastaların \%40'1nda reflü saptandı. Sağlıklı kontrolerde sol IJV'de reflü oranı \%10, hasta grupta $\% 60$ idi. MS hastalarında sağ ve/veya sol IJV'de reflü varlığı, kontrol grubuna göre istatistiksel olarak anlamlı idi. Hastalarda USG ile IJV'de reflü varlığı \%80 idi. Hastaların sağ ile sol IJV'deki reflü varlığının karşılaştırılmasından istatistiksel olarak anlamlılı elde edilmedi. USG ile KSSVY varlığını saptarken değişik sonuçlar bildirilmektedir. USG ile IJV'de tıkanma nedeni olan bir lezyon gösterilmesi MS hastalarında \%62-100 arasında bildirilirken kontrol grubunda \% 0-25, başka merkezlerde ise tıkanıklık saptanmadığı ya da düşük oranda (\%16-52) saptandığı bildirilmiştir ${ }^{19,15}$. Bu değişkenliğin sebebi, çoğu çalışmada USG'de reflünün baz alınması, faz kontrast MRV ile de reflünün tespit edilmesi, USG'de farklı teknik ve cihazın kullanılması, USG'nin yapan kişiye (eğitim, tecrübe) bağlı bir tetkik olmasından ya da kullanılan kriterlerden kaynaklanmaktadır. Merkezler arası sonuçların doğrulanmasını sağlamak için standart bir metod ve kriterlerden oluşan protokollerin oluşturulması gerekmektedir. Doepp ve arkadaşları ${ }^{20} 56$ MS ve 20 sağlıklı kişiye transkraniyal ve ekstrakraniyal sonografi ile ekstrakraniyal venöz yapıların otururken ve yatarken debileri incelediğinde, otururken MS hastalarında debinin kontrol grubundan daha yüksek olduğu, yatar konumda ise her iki grupta anlamlı fark saptamadıklarını belirtmişlerdir. 


\section{E. Kaygılı Öksüz, ark.}

Çalışmamızda çap açısından hasta ve sağlıklı kontrol grubu arası istatistiksel olarak farklılık yokken, debi açısından hastaların sadece sağ IJV debileri sağlıklılardan istatistiksel olarak yüksek idi. Literatürde USG'de IJV'nin çap ve debisinin ele alındığı başka çalışma bulunmamaktadır. Çalışmamızda MS hastalarında sadece sağ IJV'de debiyi yüksek bulmamıza rağmen USG'de IJV'nin çap ve debisine bakılmasının KSSVY tanısı ya da venöz hemodinamik bozukluklar konusunda bugünkü veriler dahilinde yol göstermediği kanaatindeyiz.

Hojnacki ve ark. ${ }^{8}$ sağlıklı grupta DS, 2D-Time-OfFlight venografi (TOF) ve 3D-Time Resolved Imaging of Contrast Kinetics angiografi (TRICKS), hasta gruba ilave olarak SV de yaptıkları çalışmalarında; MS hastalarının hepsinde, sağlıklı kişilerden birinde KSSVY saptanmıș ve SV ile doğrulanmıștır. MRV sonuçları, SV ve DS ile karşılaştırıldığında; SV'nin MS hastalarında KSSVY tanısı için altın standart olduğu; MRV ile MS hastalarında KSSVY tanısı koymanın bazı kısıtlılıklarının olduğu; DS veya SV ile doğrulanması gerektiği kanaatine varmışlardır.

Literatürde venöz anormaliklerin gösterilmesinde USG ve MRV sıklıkta kullanılmıștır. Servikal MRV ile yapılan birçok çalışma vardır. Bu çalışmalarda IJV morfolojisi ve kollateral yapıları göstermede MRV'nin daha duyarlı olduğu belirtilmektedir. Literatürde intrakraniyal venöz yapıların USG ile değerlendirilmesi ve USG'de daha çok fonksiyonel anomalilerden bahsedilmesi nedeniyle MRV ile intrakraniyal venöz yapıların morfolojisine çok fazla değinilmediği için çalışmamızda kranial MRV'ye yer verilmiş ve intrakraniyal venlerin morfolojisi açısından hasta ile sağlıklı kontroller arasında istatistiksel olarak anlamlı fark saptanmamıștır. İntrakraniyal venlerin morfolojilerinin belirlenmesi açısından kranial MRV'nin iyi bir tetkik olduğunu fakat fonksiyonel olarak yol göstermediği için KSSVY tanısı konusunda pek yol gösterici bir tetkik olmadığını düşünmekteyiz.

Zambonin 65 hastaya yaptığ 1 SV'de IJV'de tek veya çift taraflı stenoz oranının \%91 (59/65) olarak belirtmişir. IJV'de anormallikler 3 kategoride sınıflandırılmıştır: İntraluminal yapısal anomali olarak web, flap, septa, membran, malforme valv; ekstraluminal olarak stenoz ve annulus; fonksiyonel olarak da reflü, çift yönlü akım, paradoks ve akım olmaması ${ }^{7}$.

Dolic ve ark. ${ }^{9} 150$ MS (104 RR, 46 PMS) ve 63 sağlıklı kontrole DS ve MRV kullanarak yaptıkları çalışmada DS ile intra-ekstrakraniyal yapısal ve fonksiyonel venöz anormallikleri MS'lilerde sağlıklılardan istatistiksel olarak daha yüksek bulmuştur. Progresif MS grubunda ekstraluminal anomali istatistiksel olarak fazla iken intraluminal ve fonksiyonel anomali açısından progresif ve RRMS grubu arasında anlamlı fark saptanmamıştır. Progresif ve progresif olmayan MS'liler arasında MRV ile saptanan kollateral sayısı açısından fark saptanmamıştır.
Kollateral dolaşımın IJV'deki fonksiyonel ve intraluminal anomalinin yüksek olmasından kaynaklandığ 1 düşünülmektedir ${ }^{22,16}$. Çalışmamı SV'de hastaların \%72'de (18/25) sağ IJV'de, \%76 (19/25)'ında sol IJV'de stenoz saptand1. Azigos vende stenoz görülme oranı \%16 (4/25) idi. (IJV/azigos vende \%50'nin üzerinde stenoz kayda değer kabul edilmiştir). Hastaların \%60 da sağ IJV de, \%48 inde sol IJV de ve \%12 sinda ise azigos vende $\% 75$ ve üzeri darlık izlendi. Azigos vende anomali olarak çalışmamızda membran, septum ve twist saptandi. Azigos vende anomali oranı \%44 olarak bulundu. Literatürde azigos vende stenoz ve anomali oranı belirten bir çalışma bulunmamaktadır. Çalışmamızda kollateral sayısı açısından bir ve üzeri kollateral saptadığımız hasta sayısı, sağ IJV için $11(\% 44)$, sol IJV için 17 (\%68) idi. Saptamış olduğumuz yüksek orandaki kolateral dolaşım varlığ1, hastalarda saptadığımız reflünün bir göstergesi olabilir. Selektif venografi sadece hasta gruba yapıldı̆̆ 1 için bulunan anormalliklerin sağlıklı grupta ne oranda olduğu ve bunun istatistiksel olarak anlamlılığı konusunda bir şey söylemek mümkün olmamıştır . Literatür bilgileri KSSVY varlığı ve sıklığı konusunda çok farklı sonuçlar bildirmektedir. Bazı çalışmalarda MS hastalarının \%90-100'de olduğu ve kontrol grubunda hiç olmadığı şeklinde bir bilgi olduğu gibi MS hastalarının \%56'sında varken kontrol grununda \%23 olarak bildirildiği bir çalışma da vardır. Simka M ve ark. ${ }^{23}$ tarafindan 70 MS hastasına (49 RRMS, 5 PPMS ve 16 sekonder PMS) ekstrakranial DS yapıldığında venöz yetmezlik için tanımlanan 5 kriterden en az ikisini karşılayan 63 hasta ( \%90) saptanması üzerine MS ve KSSVY arasında güçlü bir ilişki olduğu öne sürülmüş; KSSVY'ye neden olan genel patoloji olarak terse çevrilmiş valf üzerinde durulmuştur. Zivadinov ve ark. $^{24,17}$ tarafindan 500 katılımcı ile yapilan transkraniyal ve ekstrakraniyal DS ile yapılan çalışmada KSSVY MS hastalarında oranı $\% 56.4$, sağlıklı kişilerde \%22.4 olarak saptanmış ve KSSVY'nin varlığ 1 hastalığın ilerlemesi ile ilişkilendirilmiştir. Literatürlerde USG tekniği ile Zamboni'nin 5 hemodinamik kriteri baz alınarak 2 kriter ve üzerinde anormallik saptanan hastalar KSSVY pozitif kabul edilirken biz USG tekniği ile intrakranial ve ekstrakranial yapılarda reflü dışında anormallik saptayamadığımız için hem hasta hem sağlıklı kontrol grubunda USG'ye göre KSSVY kriterleri karşılanmazken MS grubunda selektif venografide IJV ve azigos vende anormallikler görülmesi, USG'nin yapan kişiye, cihaza çok bağımlı olması nedeniyle çalışmamızda selektif venografide saptanan anormallikler ile USG'de saptanan reflü kombine ederek 5 parametreden 2'sini karşılayan hastalar KSSVY pozitif kabul edilmiş ve hastalarda KSSVY görülme oranı \%76 (19/25) olarak saptanmıştır

Bizim çalışmamızda hastaların IJV de reflü varlığı ile hastalık süresi, EDSS, lezyon yerleşimi, atak sayısı, cinsiyet karşılaştırılmasında istatistiksel olarak anlamlı 
bir ilişki saptanmadı. Literatürde reflü hastalık süresi, atak sayısı, cinsiyet değerlendirilmesi hiç yapılamamışken; lezyon yerleşimi benzeri olarak hastanın atak semptomu ile yapılan bir çalışmada hastanın semptomuna göre KSSVY hemodinamik tiplerin değiştiği belirtilmiştir. Fakat bizim çalışmamızda lezyon yerleşimi ile reflü ve stenoz arasında istatistiksel olarak anlamlı ilişki saptanmadı. Bu bizim hasta grubumuzun sadece RRMS' lilerden oluşmasından ve hasta sayımızın az olmasından kaynaklanmış olabiliceği düşünüldü. Hastaların IJV' de debi ve çaplarının hastalık süresi, EDSS, lezyon yerleşimi, atak sayısı, cinsiyet ile karş1laştırılmasında istatistiksel olarak anlamlı bir ilişki bulunmadı. Literatürde çap ve debi değerlendirilmesi hiç yapılmadığı için hastalık şiddeti ile ilişkisi bilinmemektedir. (Tablo-V)

Tablo V. Literatürde MS-KSSVY sıklığ 1

\begin{tabular}{|c|c|c|c|c|c|}
\hline \multirow[t]{2}{*}{ Araştırmacı(kaynak) } & \multicolumn{2}{|c|}{ MS hastas! } & \multicolumn{2}{|c|}{ Kontrol } & \multirow[t]{2}{*}{ Yöntem } \\
\hline & KssVY & Total & KSSVY & Total & \\
\hline Zamboni ve ark. 2009 & $65(\% 100)$ & 65 & $0(\% 0)$ & 235 & DS.SV \\
\hline Zivadinov ve ark. 2011 & $162(\% 56,1)$ & 289 & $374(\% 22,7) \quad 1$ & 163 & DS \\
\hline Doepp ve ark. 2011 & $0(\% 0)$ & 56 & $O(\% 0)$ & 20 & DS \\
\hline Mayer ve ark. 2011 & $0(\% 0)$ & 20 & $1(\% 5)$ & 20 & DS \\
\hline Yamout ve ark. 2010 & $19(\% 45)$ & 42 & - &.- & sv \\
\hline Baracchini ve ark 2011 & $8(\% 16)$ & 50 & $1(\% 2)$ & 50 & DS, SV \\
\hline Al-omari ve ark 2010 & $21(\% 84)$ & 25 & $0(\% 0)$ & 25 & DS \\
\hline Simka ve ark 2010 & $64(\% 91)$ & 70 & - & - & DS \\
\hline Bastianello ve ark 2011 & $610(\% 86)$ & 710 & - & - & os \\
\hline Çalismmamiz 2012. & $19(\% 76)$ & 25 & -. & -.. & DS.SV \\
\hline
\end{tabular}

Anjiografide saptanan IJV/azigos vende stenoz, kollateral, azigos vende anormalli varlığı ile hastaların EDSS, hastalık yaşı, atak sayısı, lezyon yerleşimi, cinsiyet karşılaştırılmasında istatistiksel olarak anlamlı bir ilişki bulunmadı. Bu sonuç, çalışmamızda sadece RRMS hastalarının olmasından ya da hasta sayımızın az olmasından kaynaklanıyor olabilir.

Literatürde atak sayısı ile venöz anomali ilişskisi hiç değerlendirilmemiştir. Bir çalışmada hastaların venöz anomalilerinin düzeltilmesi neticesinde hastaların ataksızlık oranlarının artığı ve lezyon yüklerinde azalma olduğu iddia edilmesi üzerine hastalarımızda atak sayısı ile venöz anomali ilişkisini değerlendirdiğimizde istatistiksel olarak anlamlı bir ilişki saptanmamıştır. Zamboni ve ark. ${ }^{11}$ tarafından hemodinamik tiplerin MS alt tiplerinde önemli farklılıklar gösterdiğini belirterek KSSVY hemodinamik parametreler oluşturmuş 4 tip hemodinamik parametre tanımlanmıştır. MS hastalarında KSSVY de hemodinamik tipler klinik gidiş ve hastalık başlangıç semptomu ile korelasyonu değerlendirildiğinde optik nörit de en s1k patern A ve B, beyin prankim ve/veya serebellar tutu- lum daha çok tip B, spinal kord tutulumlu olgularda tip D görülürken RRMS olgularında tip A ve B, SPMS de ise tip C'nin sık görüldüğü belirtilmiştir.

Zamboni'nin MS alt tiplerine göre selektif venografide stenozun Azigos ve IJV de görüldüğü yere göre yapılan KSSVY tipi belirlenmiştir. Bizim KSSVY pozitif saptadığımız MS hastalarını $\% 8(n=2)$ inde tip A, \%16(n=4) tip B, \%52(n=13) tip C KSSVY bulundu. $\mathrm{Bu}$ Zamboni'nin MS alt tiplerinde KSSVY hemodinamik tiplerinin değişiklik gösterdiği hipotezi ile çelişmektedir. Bu çelişkinin hasta sayısının az olmasından kaynaklandığı düşünüldü.

Sonuç olarak; Zambonin kriterleri kullanılarak yapılan USG'de hastalarda herhangi yapısal bir anormallik olmaksızın sadece IJV'de reflü saptanmasına rağmen SV'de stenoz ve anomali saptamış olmamız, USG'nin klinik deneyime çok bağımlı ve yapısal anomalileri göstermede zayıf olması nedeniyle başka bir tetkik ile kombine edilmesi gerektiği düşüncesindeyiz. USG'de reflü pozitif hastalara SV yapılarak KSSVY tanısı konulması uygun olabilir. Girişimsel olmaması nedeniyle USG tarama yöntemi olarak kullanılabilir.

USG ile yapılan değerlendirmede MS hastalarında sağlıklı kontrollere göre fonksiyonel olarak IJV'de anormallik olduğu, yapısal olarak venografide ciddi patolojilerinin bulunduğu görülmüştür. Sağlıklı kontrol gruba SV yapılamadığı için bu yapısal anormalliklerin MS hastasına özgü bir patoloji mi yoksa herkeste olabilecek fizyolojik bir varyasyon olup olmadığını söylemek mümkün değildir. Buna karar vermek için incelemeleri ilerletmek MS ve KSSVY arasındaki ilişkiyi ve/veya bunun MS belirtileri üzerindeki etkilerini saptamak için daha çok sayıda hastada yapılacak geniş çalışmalara ihtiyaç olduğu düşüncesindeyiz.

\section{Teşekkür}

Uludağ Üniversitesi Rektörlüğü Bilimsel Araştırma Projeleri Komisyonu'na çalışmamızda hastalara yapılan tetkikler için gerekli olan mali desteklerinden dolayı teşekkür ederiz.

\section{Etik Kurul Onay Bilgisi:}

Onaylayan Kurul: Uludağ Üniversitesi Tıp Fakültesi Araştırma Etik Kurulu.

Onay Tarihi: 08.02 .2011

Karar No: 2011-4/3

\section{Kaynaklar}

1. Lassmann H, Brück W and Lucchinetti CF. The immunopathology of multiple sclerosis: an overview. Brain Pathol 2007;17:210-8.

2. Türk Börü U, Alp R, Sur H. and Gül L. Prevalence of multiple sclerosis door-to-door survey in Maltepe, Istanbul, Türkey. Neuroepidemiology, 2006;27:17-21. 


\section{E. Kaygılı Öksüz, ark.}

3. Kabat EA, Glusman M and Knaub V. Immunochemical estimation of albumin and gamma globulin in normal and pathological cerebrospinal fluid. Fed Proc 1948;7:306.

4. Zamboni P, Menegatti E, Bartolomei I, et al. Intracranial venous haemodynamics in multiple sclerosis. Current Neuro vasc. Research 2007;4: 252-8

5. Zamboni P. The big idea: iron-dependent inflammation in venous disease and proposed parallels in multiple sclerosis. J R Soc Med. 2006;99:589-93

6. Zamboni P, Lanzara S, Mascoli F, Caggiati A, Liboni A. Inflammation in venous disease. Int Angiol 2008;27:361-93

7. Zamboni P, Galeotti R, Menegatti E, et al. Chronic cerebrospinal venous insufficiency in patients with multiple sclerosis. $\mathrm{J}$ Neurol Neurosurg Psychiatry 2009;80:392-99

8. Hojnacki D, Zamboni P, Lopez-Soriano A, et al. Use of neck magnetic resonance venography, Doppler sonography and selective venography for diagnosis of chronic cerebrospinal venous insufficiency: a pilot study in multiple sclerosis patients and healthy controls. Int Angiol 2010;29:127-39.

9. Dolic K, Marr K, Valnarov V, et al. Sensitivity and specificity for screening of chronic cerebrospinal venous insufficiency using a multimodal non-invasive imaging approach in patients with multiple sclerosis. Funct Neurol. 2011;26:205-14

10. Doepp F, Würfel JT, Pfueller CF, et al. Venous drainage in multiple sclerosis: a combined MRI and ultrasound study. Neurology. 2011;77:1745-51.

11. Traboulsee AL et all. Prevalence of extracranial venous narrowing on catheter venography in people with multiple sclerosis, their siblings, and unrelated healthy controls: a blinded, case-control study. Lancet. 2014 Jan 11;383(9912):138-45

12. Zamboni P, Menegatti E, Galeotti R, et al. The value of cerebral Doppler venous haemodynamics in the assessment of multiple sclerosis. J Neurol Sci 2009;282:21-7.

13. Al-Omari $\mathrm{MH}$, Rousan LA. Internal jugular vein morphology and hemodynamics in patients with multiple sclerosis. Int Anjiol $2010 ; 29: 115-20$
14. Baracchini C, Perini P, Calabrese $M$, et al. No evidence of al.chronic cerebrospinal venous insufficiency in clinically isolated syndrome suggestive of MS. Ann Neurol 2011;69:90-9

15. Sundsrom P, Wahlin A, Ambarki K, et al. Venous and cerebrospinal fluid flow in multiple sclerosis: a case-control study. Ann Neurol 2010; 68: 255-9.

16. Zaniewski M, Kostecki J, Kuczmik W, et al. Neck duplex Doppler ultrasound evaluation for assessing chronic cerebrospinal venous insufficiency in multiple sclerosis patients. Phlebology 2012;22.

17. Georgios Tsivgoulis et all. Chronic cerebrospinal venous insufficiency and multiple sclerosis: a comprehensive metaanalysis of case--control studies. Ther Adv Neurol Disord. 2014 Mar; 7(2): 114-136.

18. Bastianello S, Romani A, Viselner G, et al. Chronic cerebrospinal venous insufficiency in multiple sclerosis: clinical correlates from a multicenter study. BMC Neurol 2011;11:132.

19. Nicolaides AN, Morovic S, Menegatti E, Viselner G, Zamboni P. Screening for chronic cerebrospinal venous insufficiency (CCSVI) using ultrasound: recommendations for a protocol. Funct Neurol. 2011;26:229-48.

20. Doepp F, Paul F, Valdueza JM, et al. No cerebrocervical venous congestion in patients with multiple sclerosis. Ann Neurol 2010;68: 173-83

21. Neglen P, Darcey R, Olivier J, Raju S. Bilateral stenting at the iliocaval confluence. J Vasc Surg. 2010;51:1457-66

22. Zamboni P, Galeotti R, Menegatti E, et al. A prospective openlabel study of endovascular treatment of chronic cerebrospinal venous insufficiency. J Vasc Surg 2009;50:1348-58.

23. Simka M, Kostecki J, Zaniewski M et al. Extracranial Doppler sonographic criteria of chronic cerebrospinal venous insufficiency in the patients with multiple sclerosis. Int Angiol 2010 29:109-14.

24. Zivadinov R, Marr K, Cutter G, et al. Prevalence, sensitivity, and specificity of chronic cerebrospinal venous insufficiency in MS. Neurology 2011;77:138-44 